
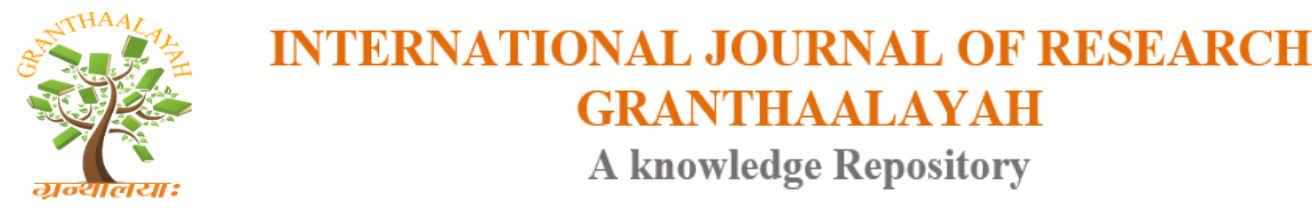

Management

\title{
DIGITAL DIVIDE: A GENDERED GULF BETWEEN MALE AND FEMALE IN INTERNET USAGE
}

\author{
Ummuhabeeba Chaliyan *1 \\ ${ }^{* 1}$ Assistant Professor, Department of Economics, JM College of Arts and Science, Tirur Kerala, \\ India
}

\begin{abstract}
This paper quantifies and analyses the issue gender digital divide which has been prominent in discussions of the information society. The phenomena digital divide can in brief be defined as inequality of Internet access. But access alone does not solve anything; the actual problem about digital divide is very complex. While it would be very interesting to explore the relationship between the digital divide and gender identity among the multiple faces of digital divide based on age, job, nation, education etc. Researchers were quick to observe that women tend to be latecomers to the digital age. As a consequence, the new technology was popularly portrayed as a male domain.
\end{abstract}

Keywords: Gender Digital Divide; Information and Communication Technologies; Women Empowerment; Chi Square.

Cite This Article: Ummuhabeeba Chaliyan. (2018). "DIGITAL DIVIDE: A GENDERED GULF BETWEEN MALE AND FEMALE IN INTERNET USAGE." International Journal of Research - Granthaalayah, 6(5), 9-16. https://doi.org/10.29121/granthaalayah.v6.i5.2018.1415.

\section{Introduction}

As digital technologies have increased in prevalence and importance, a digital divide has emerged along the lines of previously existing social divides. In other words, these new technologies have benefited those who already had access to other resources at greater rates than people who had fewer resources (de Haan, 2004; van Dijk, 2006). Thus, this divide reproduced the already extant inequalities between rich and poor, urban and rural, male and female (e.g., Hoffman \& Novak, 1998; Howard, Rainie, \& Jones, 2001; Katz \& Aspden, 1997; LaRose, Gregg, Strover, Straubhaar, Carpenter, 2007). These digital gaps may exacerbate existent inequalities between social groups because new technologies provide opportunities to access information, a necessary tool for participating in a democratic society, as well as access to trade, education, job opportunities, health care information, and information about government programs.

One of the most enduring technological inequalities is the gender divide. Research has detailed a variety of ways in which women lag men in the ownership of technology and the development of 
technological skills. For example, men own and use computers and the internet more than women, spend more time online, take more technology classes, and show more motivation to learn digital skills (Cooper, 2006; Correa, 2010; Fallows, 2005; Livingstone \& Helsper, 2007; Losh, 2004; Pinkard, 2005; Wilson, Wallin, \& Reiser, 2003). Giddens' structuration theory (1984) helps establish that even has individuals have the agency to pursue their desires, social structures can influence their behaviors and the way they think about objects such s technology. There are also cultural and psychological factors that may constrain certain people, such as women, from using technologies even when they have access (Terry \& Gomez, 2010).

The debate on the digital divide has moved beyond the concept of a gap between a literal access gap in digital technologies to pay closer attention to a multifaceted concept of access that involves cognitive and social access, which may shed light on the reasons behind the digital divide (Hargittai, 2002; Newhagen \& Bucy, 2004; van Dijk, 2006). Cognitive access refers to individual resources used to access the technology (e.g. attitudes, anxiety and skills). Social access refers to the cultural norms and social resources embedded in a social group (Newhagen \& Bucy, 2004).

Despite having different approaches, many scholars have suggested that relationships with technology are gendered. Some even argue that the phenomenon of technology itself cannot be fully understood without reference to the gender. The social construction of technology (SCOT) theory (Mackenzie \& Wajcman, 1985; Pinch \& Bijker, 1984) suggests that technology is socially shaped according to different social contexts; the way society is structured informs the technological shapes, designs, and meanings. Social construction theories try to explicitly counteract the tendency to see technology itself as determinant of social outcomes and uses.

Regarding attitudes toward technology, there are no major gender differences in the actual abilities to locate online content in an effective and efficient way (Hargittai \& Steven, 2006). However, women perceive that their abilities are significantly lower than men's (Cooper, 2006; Correa, 2010; Hargittai \& Shafer, 2006; Lunt \& Livingstone, 1996), which eventually may affect their motivation and online behaviour. Similarly, while women's interest in computers and technology has increased, they still feel more uncomfortable with technology than men ( Colly \& Comper, 2003; Cooper\& and weaver, 2003).

Research on the gender divide points to the social development of boys and the girls and the social expectations and stereotypes about what is appropriate for both genders (Cooper, 2006; Meraz, 200). Generally, children are socialized to computers through video games. Video games are not only experienced through peer-learning, but educators also use them to make the learning experience in schools more enjoyable. The competitive nature of video games makes them more attractive to boys than girls. In addition, computer software is usually developed for and marketed toward males (Huff \& Cooper, 1987). As a result, boys feel more attracted to and develop more confidence with computers, while many girls develop negative attitudes, lowered interest, and anxiety (Cooper \& Weaver, 2003). In addition, the widely held stereotype that women are not good at technology may also increase their levels of anxiety and affect their performance (Cooper, 2006; Meraz, 2008).

Thus, as the issue of access to and uptake of ICTs is entwined with the gender differences (Kole 2001), the need of acknowledging these differences is crucial to overcome the digital divide. Bimber (2000) observed that men and women do adopt ICT differently but the gender gap in terms 
of ICT utilization is determined by the combination of gender and socioeconomic factors and not the gender exclusively. Due to socialisation process, women may undermine their capabilities, and as a result, be reluctant to adopt ICT. Hargittai and Shafer (2006) reported that men and women do not necessarily differ in their ICT capabilities but women's self assessed skills were significantly lower than that of men. That is why, although gender gap in terms of access to ICT has been narrowed in developed countries, concern over gender differences should not necessarily be sidelined (Ono and Zavodny 2003).

\section{Statement of the Problem}

The use of Information and Communication Technologies (ICT) is revolutionizing our daily lives, our social interactions, the services we deliver or receive, the way our kids are growing up, and the type of solutions and reach we can attain in development solutions. However a large part of the world has been deeply marginalized from accessing and using ICTs for socio-economic empowerment. This is what is commonly called the gender digital divide. Too many women are being excluded from the technological revolution. The UN estimates that some 2000 million more men have access to the internet than women and this chasm is especially wide in developing countries. The digital exclusion of women is primarily a product of social inequalities. In many global south countries, women occupy traditional roles in the home or in the primary production sector, such as farming. According to UN's report, The World's Women 2015, women are more likely than men to be unemployed or to work in the home or smallholding, which usually implies that they have little or no monetary income. In Oceania, sub Saharan Africa and southern Asia, between 30 and $55 \%$ of employed women are contributing family workers, about $20 \%$ higher than men in the same regions. With many women beginning these roles in their childhood years, their access to digital technology is limited early on and often never recovers.

A large group of working women of India is in the rural and unorganized sectors. Socially majority of rural women are still traditionally bound and are in disadvantageous position. Globalisation is opening up the Indian economy at a very high speed. During the past decades, advances in information technology have facilitated a global communication network that transcends national boundaries and has an impact on public policy, private attitudes and behaviors, especially of children and young adults. Everywhere the potential exists for the information technology to make a far greater contribution to the advancement of rural women. In Kerala the relevance of empowering women is also more important. As per the 2001 census, it counted 16.36 million females against total population of 31.83 million in which 12.12 million women live in rural area and 30 per cent of the rural women live below poverty line.

This process of digital exclusion creates barriers to prosperity. It can restrict women's ability to gain employment and use digital health and education services. There is plenty of evidence to suggest to that digital access can help boost women's personal development and wider prosperity. US president Barack Obama stated that "the internet is not a luxury, it is a necessity". Before we embark on the next steps of the global technical revolution, we must ensure that the most basic of online tools are accessible to all. We should content that something as transformative and integral to our daily lives as the internet remains out of reach for people around the world who have so much to gain in terms of their future prosperity by getting connected. 


\section{Literature Review}

Communication is the central and common starting point for the existence of both internet and democracy. The dialogue is the ideal method for democracy and Internet is an interactive media through which a dialogue can be realized. The core of the debate around Internet, as well as other media, is based on the fundamental values concerning the role of communication in society; the access has to be equally divided and all citizens has to have access to public channels of communication on equal conditions and with equal possibilities.

The term digital divide entered public discourse and became very popular in the 1990s (van Dijk, 2000). Manuel Castells, Professor of Sociology at the University of California, has in his wellknown trilogy The Information Age (1996-2000) studied the modern information technology from his point of view of the so-called digital divide. NTIA (1999) defined the digital divide as the gap between those with and those without access to ICT The digital divide describes the lack of balance between the digital technology, our environment and human society.

There are two different kinds of digital divide, according to the report spanning the Digital Divide (2001).They are International and Domestic Digital Divides. The international digital divide, the divide between countries, is usually measured in terms of PC density, computers with internet access and mobile phone users, while the domestic digital divide, the divide between groups within countries, is measured in terms of gender, age, disability, location, and income. Bridges.org argues that even if the use of and access to ICT is increasing, the "information haves" (to have or not to have access to the Internet/ICT and therefore the information) are increasing their access and use at such an exponential rate that in effect, the divide between people within countries is increasing. We aim to concentrate on the domestic digital divide to see what impact these and other factors may have on the internet users and non-users. We will also discuss the so-called Real access, meaning the key elements needed to integrate technology into society in an effective way so that people can put technology to use in improving their lives. Access to the technology itself is of course critical, but the problem is too complex to be reduced to the actual, physical access to a computer or an internet connection alone. Real access requires a number of factors in order to use the technology effectively, factors such as sustainable economy, training, a political environment which supports the development, skills in English or, at best, software in the local language. Apart from language skills, socio-culturally based inequalities such as gender, age, and ethnicity could exclude people from using the technology.

It is also important to emphasize that we cannot bridge the digital divide with a fully extended physical network alone (in itself a utopia); the real digital divide starts when you are connected. The primarily division of people is those who can use and benefit from the information and those who cannot. For those who cannot, the options are exclusion or exploitation. Having access to all that Internet has to offer does not mean that you need or can utilize it. As Castells argues, exclusion from the networks may proceed by different mechanisms: lack of technological infrastructure; economic obstacles to access the networks; insufficient educational capacity, for example. With access to the internet, you still need to know what information you want, where to find it, and then what to do with it. Bridges.org agrees in their report spanning the Digital Divide that access to technology must be about more than just computers and connections. Factors needed to consider, 
as abovementioned, are training, relevant use and content, economic, and political environment, as well as cultural such as gender, age, race, and other socio-cultural factors.

The digital divide has been an area of interdisciplinary concern, and several types of technologies have been investigated from empirical and conceptual standpoints. The main ICT discussed in this field was the internet. The reason might have been that the supply of information by the Internet is more heterogeneous and potentially unlimited than that by other ICTs while, on the other hand, access to the Internet is still restricted in many countries due to technical and economic barriers. As governments worldwide increasingly implement e-government services, concerns about the potential impact of the digital divide continue to grow. As an example, the digital divide has been identified as a major barrier to the effective deployment of e-government (Choudrie, Weerakkody \& Jones, 2005; Helbig, Gil-Garcia \& Ferro, 2009). Specifically, the issues of e-government, the ICT index, e-readiness and alternative technologies for bridging the digital divide have gradually increased, while the issue of ICT adoption and diffusion, public policy and regulation have remained important over time.

Education bridges this gap between information and knowledge, but tragically, education is also the key means by which most Africans are systematically excluded from the goods of informational capitalism, and also from full participation in any kind of network society. Castells believes that the key skills for success in the modern economy are mathematics, language and Internet literacy. Notably, the improvement in educational conditions would provide an important catalyst for sustainable digital progress (Quibriaetal.,Wijers, 2010). Policy decisions should aim to reduce inequalities in access to and use of ICTs, and they must take into consideration the necessary investment in training and support (Freese et al., 2008; Hargittai \& Hinnant, 2010). Hence, the ideas of this group strengthen the view that efforts to bridge the digital divide should not only pay attention to technological development and innovations. Rather, policymakers should holistically address matters of improving the human capital of a global society. Focusing on social, educational, diversity and skill aspects in the context of technological change will be beneficial for all stakeholders as these factors may affect economic development and country competitiveness in the long run.

\section{Objectives}

The specific objectives of the study are:

1) To understand the growth of internet usage across people.

2) To review the access and the use of internet by women particular.

3) To know the magnitude of gender disparity in the use of internet by identifying the major factors contributing the gender digital divide.

\section{Data and Methodology}

Primary data for the study is collected from 100 samples by using convenient sampling method. The study purely based on sample survey conducted among people in Kozhikode locality. Sample survey is conducted by using a structured questionnaire. The questionnaire includes all aspects of 
socio-economic background of the respondent, their education, constraints, benefits etc. Besides primary data, secondary data were collected from the various IT initiatives of Government and private agencies for promoting women participation in ICT based services and jobs. The information about different schemes related to ICTs were also collected from Kerala Women's Commission, publications of various agencies like the Centre for Development Studies(CDS, Research works, studies conducted by institutions in other states, various journals, books and publications.

To understand whether there is gender difference in the internet usage and to make the study more precise by identifying whether there is association between age and internet usage, education and internet usage among male and female $\chi^{2}$ test is again used.

\section{- Chi-square Test $(\chi 2)$}

To know whether there is difference in internet usage between male and female and to assess the association between socio-economic characteristics (education and age) of male and female, we use the Chi-square test for independence.

The hypothesis test for independence is:

Ho: The two classification variables are independent of each other.

H1: The two classification variables are not independent.

The Chi-square test statistic for independence is

$$
\chi^{2}=\sum_{i=1}^{r} \sum_{j=1}^{\mathrm{c}} \frac{\left(O_{i j}-E_{i j}\right)^{2}}{E_{i j}}
$$

With degree of freedom as (r-1) (c-1). The null hypothesis is rejected if sample $\chi^{2}$ at chosen level of significance.

\section{Results and Discussion}

This section outlines the major findings of sample survey. It examines the intensity of disparity in the use of internet between male and female. This study discusses whether variations in education and age among male and female contribute anything for the widening of gap in internet usage so that it can conclude that the severity of gendered space. Thus questionnaire used for survey includes various types of questions to know the dimensions of gender digital divide.

To assess the association between male and female in internet usage, $\chi 2$ test of independence has been performed. Test results are given.

Table 1: Disparity in internet subscription

\begin{tabular}{|c|c|c|c|}
\hline Basis & Male & Female & \multirow{4}{*}{$\begin{array}{l}\chi 2=11.14 \\
(0.0110)^{*}\end{array}$} \\
\hline Internet subscribers & 76 & 56 & \\
\hline No Connection & 24 & 44 & \\
\hline Total & 100 & 100 & \\
\hline
\end{tabular}

Source: Sample Survey 
(Figure in brackets is p-value, * indicates significance at $5 \%$ level.)

As the table suggests there is no association between male and female in internet usage. Thus there exist gender digital divide $(\chi 2=11.14, \mathrm{P}=0.0110)$

To assess the association between age and internet usage among male and female or in other words whether there is significant difference in internet usage on the basis of age, $\chi 2$ test of independence has been performed. Test results are given in table 2

Table 2: Age and Internet Usage

\begin{tabular}{|c|c|c|c|c|c|c|c|}
\hline \multirow[t]{2}{*}{ Basis } & \multicolumn{3}{|c|}{ Female } & \multicolumn{3}{|c|}{ Male } & \multirow{8}{*}{$\underset{(0.3630)^{*}}{\chi 2=16.29}$} \\
\hline & $\begin{array}{c}\text { Age } \\
\text { Distribution }\end{array}$ & $\begin{array}{c}\text { Having } \\
\text { Connection }\end{array}$ & $\begin{array}{c}\text { No } \\
\text { Connection }\end{array}$ & $\begin{array}{c}\text { Age } \\
\text { Distribution }\end{array}$ & $\begin{array}{c}\text { Having } \\
\text { Connection }\end{array}$ & $\begin{array}{c}\text { No } \\
\text { Connection }\end{array}$ & \\
\hline $\begin{array}{l}\text { Below } \\
20\end{array}$ & 28 & 24 & 4 & 32 & 20 & 12 & \\
\hline $\begin{array}{c}\text { Between } \\
20-30\end{array}$ & 28 & 24 & 4 & 32 & 20 & 12 & \\
\hline $\begin{array}{c}\text { Between } \\
30-40\end{array}$ & 28 & 20 & 8 & 24 & 12 & 12 & \\
\hline $\begin{array}{c}\text { Above } \\
40\end{array}$ & 16 & 8 & 8 & 12 & 4 & 8 & \\
\hline \multirow[t]{2}{*}{ Total } & \multirow[t]{2}{*}{100} & 76 & 24 & \multirow[t]{2}{*}{100} & 56 & 44 & \\
\hline & & & & & \multicolumn{2}{|c|}{100} & \\
\hline
\end{tabular}

\section{Source: Sample Survey}

(Figure in brackets is p-value, * indicates significance at5\% level.)

As the table suggests there is no association between age and internet usage $\left(\chi^{2}=16.29, \mathrm{P}=0.3630\right)$

To assess the association between education and internet usage among male and female or in other words whether there is significant difference in internet usage on the basis of education between male and female, $\chi 2$ test of independence has been performed. Test results are given in table 3

Table 3: Education and Internet Usage

\begin{tabular}{|c|c|c|c|c|c|c|c|}
\hline \multirow[t]{2}{*}{ Basis } & \multicolumn{3}{|l|}{ Female } & \multicolumn{3}{|l|}{ Male } & \multirow{9}{*}{$\underset{(0.2472)^{*}}{\chi 2}=29.41$} \\
\hline & Education & $\begin{array}{l}\text { Having } \\
\text { Connection }\end{array}$ & $\begin{array}{l}\text { No } \\
\text { Connection }\end{array}$ & Education & $\begin{array}{l}\text { Having } \\
\text { Connection }\end{array}$ & $\begin{array}{l}\text { No } \\
\text { Connection }\end{array}$ & \\
\hline $\begin{array}{l}\text { Lower } \\
\text { Primary }\end{array}$ & 12 & 8 & 4 & 12 & 4 & 8 & \\
\hline $\begin{array}{l}\text { Upper } \\
\text { Primary }\end{array}$ & 24 & 20 & 4 & 24 & 12 & 12 & \\
\hline $\begin{array}{l}\text { High } \\
\text { School }\end{array}$ & 28 & 24 & 4 & 28 & 16 & 12 & \\
\hline $\begin{array}{l}\text { Higher } \\
\text { Secondary }\end{array}$ & 16 & 8 & 8 & 24 & 12 & 12 & \\
\hline Graduation & 8 & 8 & 0 & 4 & 4 & 0 & \\
\hline $\begin{array}{l}\text { Above } \\
\text { graduation }\end{array}$ & 12 & 8 & 4 & 8 & 8 & 0 & \\
\hline Total & 100 & 76 & 24 & 100 & 56 & 44 & \\
\hline
\end{tabular}


Source: Sample Survey

(Figure in brackets is p-value, * indicates significance at5\% level.)

As the table suggests there is no association between education and internet usage $\left(\chi^{2}=29.41\right.$, $\mathrm{P}=0.2472$ )

\section{Conclusion}

It is true that technology is one of the developmental tools. At the same time the new technological inventions have to be properly implemented and people trained to utilize its advancement for their development. This study identifies how far there exist gender inequality in the internet usage. Even though government has taken several steps and implemented various plans and policies to bring the rural women into the IT related industry. Still a major portion deprives the benefit and exist gender digital divide. Thus it is universally accepted that ICT offers immense opportunities for the comprehensive social and economic development of society. Without its adoption, there is little chance for countries or regions to develop.

However, their ability to take advantage of these opportunities is contingent upon conducive policies, an enabling environment in their countries to extent increased educational levels, financial support, and infrastructural support along with an environment permitting equal access of fruits of technology among male and female. Hence, efforts should focus on social barriers for using modern gadgets and information technology.

\section{References}

[1] Annual Report of Human Resource Development, Government of India, 2011-12

[2] Annual Report of Human Resource Development, Government of India, 2012-13

[3] Eswar R, Patnaik B (2006). "Empowerment of Women in Orissa: A Case Study of Koraput District", Women Empowerment, Panigrahy R.L, Dasarathi Bhuyan, Discovery Publishing House, New Delhi pp.43-56.

[4] VAPS. Enhancing Women Empowerment through Information and Communication TechnologyA Report.

[5] Venugopal, Vijesh(2014). "ICT-A Sustainable Strategy for Women Empowerment in Kerala" in International Journal of Sociology and Anthropology 4(9) 270-280

\footnotetext{
*Corresponding author.

E-mail address: habeebavenkulam@gmail.com
} 